\title{
Prospective controlled trial of duplicated $(J)$ versus quadruplicated (W) pelvic ileal reservoirs in restorative proctocolectomy for ulcerative colitis
}

\author{
D Johnston, M E R Williamson, W G Lewis, A S Miller, P M Sagar, P J Holdsworth
}

\begin{abstract}
Aims-A prospective randomised controlled trial was conducted to find out what influence the design of the pelvic reservoir had on the functional outcome. Patients and Methods-Sixty patients received either a duplicated (J) or a quadruplicated (W) reservoir, constructed with either 30 or $40 \mathrm{~cm}$ of ileum. Each patient underwent laboratory tests of anorectal function before and one year after operation.

Results-One year after operation, 57 patients were available for assessment: each had good anal continence, though eight experienced minor leakage of mucus, and all were able to defer defecation for more than 15 minutes. Median bowel frequency in 24 hours (IQR) in patients with J reservoirs (5 (4-7)) did not differ significantly from that of patients with $W$ reservoirs (5 (4-6)). Likewise, bowel frequency in patients with the smaller $(30 \mathrm{~cm})$ reservoirs did not differ significantly from bowel frequency in patients with the larger $(40 \mathrm{~cm})$ reservoirs. However, patients with large W40 reservoirs had the lowest bowel frequency of the four groups (median 4 per 24 hours, $p=N S)$. The capacity and compliance of the W40 reservoirs were greater than those of the other types of reservoir, but the differences were not statistically significant.
\end{abstract}

Conclusions-These findings provide support for the use of a relatively small (30 cm), duplicated (J) ileal reservoir, which is simple to construct with linear stapling instruments.

(Gut 1996; 39: 242-247)

Keywords: ulcerative colitis, ileal reservoir.

Eighteen years after Parks and Nicholls first introduced the pelvic ileal reservoir into clinical practice, ${ }^{1}$ there is still no consensus about the ideal design of the reservoir. Two designs - the duplicated $(J)$ and the quadruplicated (W) reservoir (Fig 1) - have been found to possess advantages over the original triplicated (S) reservoir. ${ }^{23}$ In our own experience, ${ }^{4-6}$ the $W$ reservoir constructed with $40 \mathrm{~cm}$ of ileum was associated with a lower bowel frequency ( 4 in 24 hours) than the $\mathrm{J}$ reservoir (6 in 24 hours). However, in the only prospective randomised trial that has been reported, no significant difference in clinical outcome was found when the $J$ and $\mathrm{W}$ reservoirs were compared. ${ }^{7}$ Although no randomised trial of the use of different lengths of ileum for construction of the reservoir has been performed, reports that bowel frequency is inversely proportional to the capacity of the reservoir ${ }^{4}$ would tend to favour the construction of larger reservoirs.

The aim of this study was to find out if the functional outcome after restorative proctocolectomy is related to the design of the reservoir and the length of ileum used in its construction. Our hypothesis was that a quadruplicated (W) design would produce a more capacious reservoir than a duplicated (J) one, when the same length of ileum was used in their construction. Assuming that bowel frequency is inversely related to the capacity of the reservoir, we predicted that patients with a W reservoir would have a lower bowel frequency than patients with a J reservoir.

\section{Methods}

A consecutive series of 60 patients with ulcerative colitis was studied (the diagnosis was later revised in five patients, see later). They were randomised to receive one of four types of reservoir: (1) Duplicated reservoir made with $30 \mathrm{~cm}$ of ileum (J30). (2) Duplicated reservoir made with $40 \mathrm{~cm}$ of ileum (J40). (3) Quadruplicated reservoir, 
TABLE I Details of the 60 patients

\begin{tabular}{|c|c|c|c|c|}
\hline Reservior design & $\mathfrak{7 3 0}$ & $\mathfrak{f 4 0}$ & W30 & $W 40$ \\
\hline Number & 14 & 17 & 15 & 14 \\
\hline Age $(y)$ & $32(24-62)$ & $32(25-43)$ & $33(24-50)$ & $33^{\star}(10-59)$ \\
\hline Sex m:f & $5: 9$ & $7: 10$ & $7: 8$ & $7: 7$ \\
\hline \multicolumn{5}{|l|}{ Diagnosisf } \\
\hline Ulcerative colitis & 14 & 15 & 12 & 14 \\
\hline Indeterminate colitis & 0 & 0 & 3 & 0 \\
\hline Crohn's disease & 0 & 2 & 0 & 0 \\
\hline Previous colectomy & 1 & 3 & 3 & 5 \\
\hline One stage RP & 7 & 5 & 5 & 6 \\
\hline Eversion of anorectum & 10 & 14 & 9 & 10 \\
\hline
\end{tabular}

J30, J40, W30, and W40: see text. * Median (range). †Before operation, all patients had been diagnosed as having either ulcerative colitis or indeterminate colitis. One stage RP: no defunctioning ileostomy was used. Eversion of anorectum: temporary eversion of the anorectum through the anus in the course of the operation.

$30 \mathrm{~cm}$ of ileum (W30). (4) Quadruplicated reservoir, $40 \mathrm{~cm}$ of ileum (W40). Table I shows details of the patients. Two patients proved to have Crohn's disease and three, indeterminate colitis, when the resected specimen was examined pathologically.

\section{Operative technique}

The J reservoirs were constructed with the aid of the GIA linear stapler (Autosuture, Ascot, UK): the staple lines were inverted with 3-0 Maxon. ${ }^{2}$ The $\mathrm{W}$ reservoirs were constructed by hand suture in two layers, ${ }^{3}$ an all layer catgut suture being oversewn with a seromuscular layer of 3-0 Maxon (Cyanamed GB Ltd, Gosport, Hants). The rectum was removed by close perimuscular dissection in an attempt to avoid autonomic nerve damage. In each patient, a stapled, end to end pouchanal anastomosis was constructed as we described previously, ${ }^{8}$ temporary eversion of the anorectum being used in most patients during the course of the operation in an attempt to site the pouch-anal anastomosis accurately 1 to $1.5 \mathrm{~cm}$ above the dentate line. ${ }^{9}$ A defunctioning ileostomy was not used if the surgeon was satisfied with the integrity of this anastomosis ('doughnuts' intact, airtight and watertight on testing), and if the patient was medically fit, well nourished and not receiving high dose corticosteroid therapy. Thirty seven patients received an ileostomy and $23 \mathrm{did}$ not.

\section{Laboratory studies}

Each patient underwent tests of anorectal function in the laboratory before operation $^{6-10}$ and these were repeated in 50 patients one year after restorative proctocolectomy or closure of the defunctioning ileostomy. Seven patients declined to have the anorectal physiological assessment repeated one year after operation. Three patients are not yet one year from the operation.

Resting anal sphincter pressure was measured at $1 \mathrm{~cm}$ intervals along the anal canal by means of a $5 \mathrm{~mm}$ diameter water filled balloon. The pressure at each station was measured for at least one minute or until the recording became stable. Pressure in the system was transmitted via a transducer and amplifier (3552 Ormed
Ltd, Welwyn Garden City, UK) to a chart recorder (5041 Ormed Ltd). ${ }^{8}$

Threshold electrosensitivity of the mucosa of the anal canal was measured in the upper, mid and lower anal canal (as determined by anal manometry) by means of a bipolar constant current stimulator probe lubricated with a solution of KY Jelly (Johnson and Johnson, Slough, UK) and normal saline in equal quantities. 1011

Capacity and compliance of the reservoir were measured by means of a latex balloon $7.5 \mathrm{~cm}$ in length, which was attached to a 14 FG catheter, similar to that used for anal manometry. Pressures within the balloon were transmitted to a Gould Statham P-50 pressure transducer (Spectramed, UK) and recorded on a Lectromed chart recorder (Multitrace 4; Lectromed Ltd, Jersey UK). The balloon and catheter were inserted into the anal canal with the patient in the left lateral position. The catheter was advanced until the base of the balloon was at least $5 \mathrm{~cm}$ from the anal verge. The balloon was then inflated slowly with air at a constant rate of $1 \mathrm{ml}$ per second to determine the functional capacity (first sensation) and the maximum tolerated volume (unequivocal desire to defecate). The ratio of change in volume to change in pressure was estimated from the baseline curve on the Lectromed chart and used as an index of compliance.

Rectoanal inhibitory reflex was assessed by measuring the response of the upper anal sphincter to distension with air of a balloon within the rectum or ileal reservoir at a rate of $1 \mathrm{ml}$ per second. A 20 per cent decrease in pressure was taken to denote a positive reflex. $^{12}$

\section{Clinical assessment of outcome}

The quality of anal continence was assessed one year after operation or closure of the defunctioning ileostomy in 57 patients, by one or other of three clinicians who had not been part of the surgical team (WGL, MERW, ASM) and who were not aware of the results of the laboratory tests. In two patients, the operation was a failure: each required a permanent ileostomy on account of pelvic sepsis. A third patient has been followed up for less than one year since reversal of the ileostomy. Each patient was questioned about faecal leakage, anal soreness, the ability to defer defecation, and whether he or she could not only discriminate between flatus and faeces, but actually release flatus safely while standing or sitting, without fear of even the most minor leakage.

\section{Statistical analysis}

Grouped data were expressed as median and interquartile range. Differences between groups were assessed by the Mann-Whitney $\mathrm{U}$ test. The correlation between different variables was determined by means of Spearman's rank correlation. ${ }^{13}$ 


\section{Results}

\section{CLINICAL RESULTS}

Morbidity and mortality (Table II)

There was no operative mortality. Morbidity was similar in the four groups of patients. The operation failed in two patients with a J reservoir

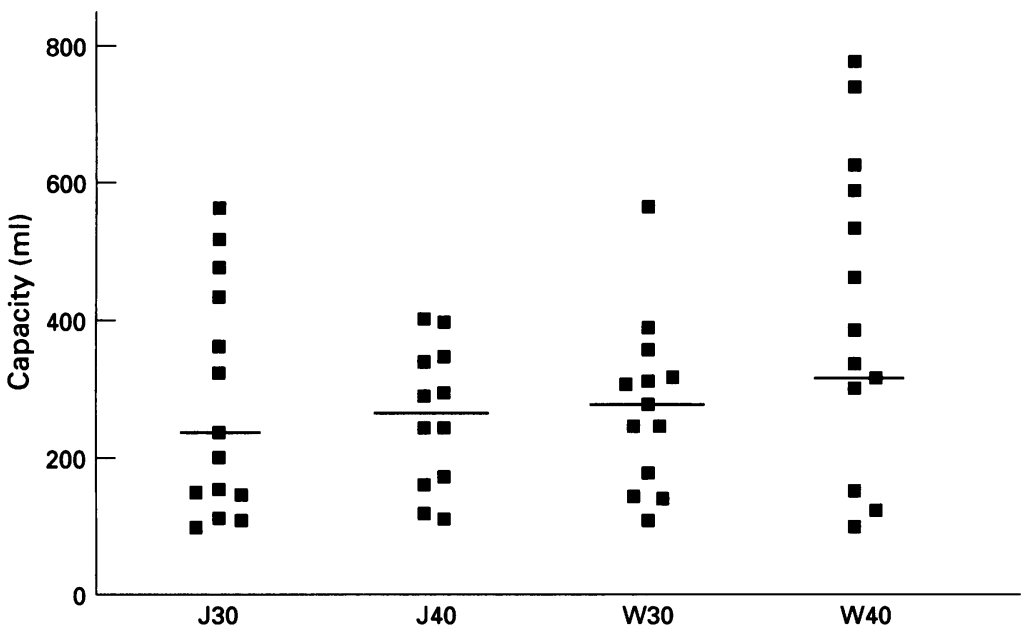

Figure 2: Capacity of the ileal reservoirs in the four groups of patients one year after restorative proctocolectomy $(p=N S)$. Note the similar median values, but also the wide range that exists within each group.

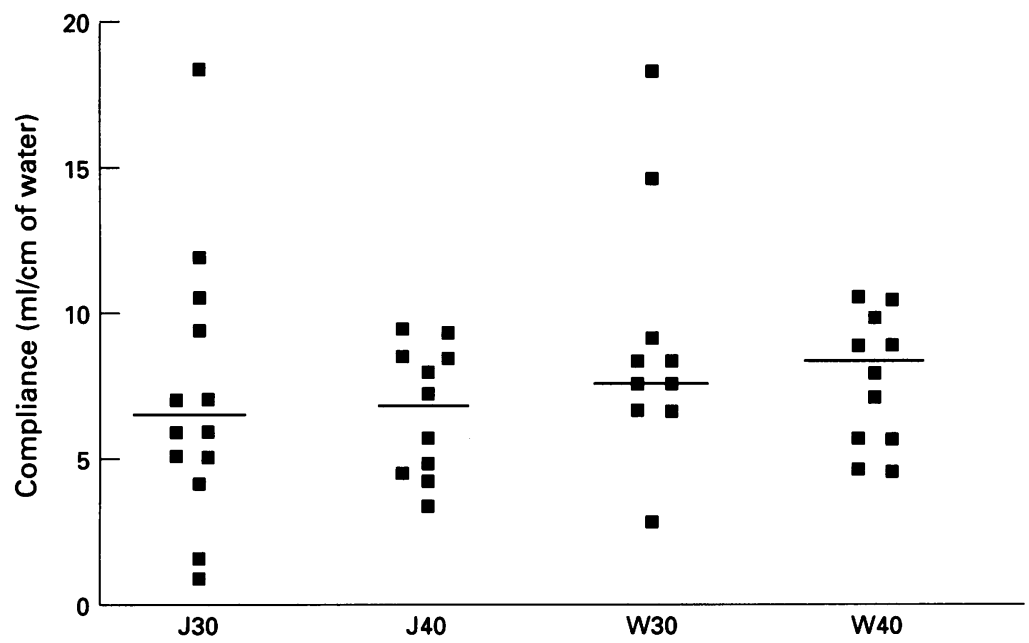

Figure 3: Compliance of the ileal reservoirs in the four groups of patients one year after restorative proctocolectomy $(p=N S)$.

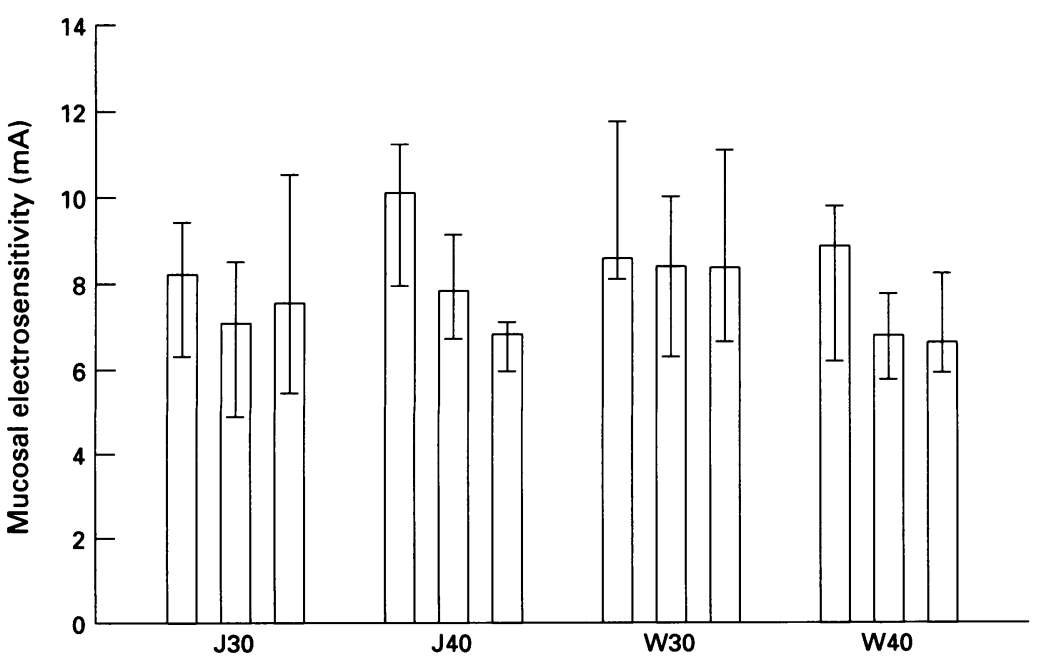

Figure 4: Sensation (threshold mucosal electrosensitivity) in the upper, mid, and lower anal canal in the four groups of patients one year after restorative proctocolectomy $(p=N S)$. made from $40 \mathrm{~cm}$ of ileum: both developed pelvic sepsis after operation and both subsequently experienced poor function in terms of excessive bowel frequency and urgent defecation, which necessitated excision of the reservoir and construction of a permanent ileostomy.

\section{LABORATORY TESTS}

(a) Function of the pelvic reservoirs Capacity and compliance of the reservoirs (Figs 2 and 3)

$\mathcal{F}$ reservoirs compared with $W$ reservoirs - the capacity and compliance of the J reservoirs did not differ significantly from the capacity and compliance of the $W$ reservoirs. The median (interquartile range) capacity of the J reservoirs was $250(180-365) \mathrm{ml}$ compared with 300 $(170-398) \mathrm{ml}$ for the $\mathrm{W}$ reservoirs $(p=N S)$. The median compliance of the $J$ reservoirs was $6.7(5 \cdot 2-8.9) \mathrm{ml} / \mathrm{cm} \mathrm{H} \mathrm{H}_{2} \mathrm{O}$ compared with 7.6 $(6 \cdot 2-10 \cdot 2) \mathrm{ml} / \mathrm{cm} \mathrm{H}_{2} \mathrm{O}$ for the $\mathrm{W}$ reservoirs $(\mathrm{p}=\mathrm{NS})$.

Thirty centimetre reservoirs compared with 40 centimetre reservoirs - no significant differences were found between the two sizes of reservoir. The median (interquartile range) capacity of the $30 \mathrm{~cm}$ reservoirs was $250(176-374) \mathrm{ml}$, compared with $300(191-416) \mathrm{ml}$ for the 40 $\mathrm{cm}$ reservoirs $(p=N S)$. The median compliance of the $30 \mathrm{~cm}$ reservoirs was 6.7 (5.2-8.9) $\mathrm{ml} / \mathrm{cm} \mathrm{H}_{2} \mathrm{O}$ compared with 7.5 $(5 \cdot 2-9 \cdot 8) \mathrm{ml} / \mathrm{cm} \mathrm{H}_{2} \mathrm{O}$ for the $\mathrm{W}$ reservoirs $(\mathrm{p}=\mathrm{NS})$.

Comparison of all four designs of reservoir both capacity and compliance of the quadruplicated W reservoir made with $40 \mathrm{~cm}$ of ileum were greater than the capacity and compliance of either type of $J$ reservoir and of the W30 reservoir, but the differences were not statistically significant (Figs 2 and 3).

\section{(b) Anal sphincter function}

Motor function - median maximum resting anal pressures before and one year after operation were $105(89-115) v 58(50-90) \mathrm{cm} \mathrm{H}_{2} \mathrm{O}$ $(\mathrm{p}=\mathrm{NS})$ after $\mathrm{J} 30$ construction, $112(79-131)$ v $71(53-88) \quad \mathrm{cm} \mathrm{H} \mathrm{H}_{2} \mathrm{O}(\mathrm{p}=0.008, \mathrm{~J} 40), 88$ (54-94) v 57 (46-64) $\mathrm{cm} \mathrm{H}_{2} \mathrm{O}$ ( $\mathrm{p}=\mathrm{NS}$, W30), and $76(50-95) v 73(42-81) \mathrm{cm} \mathrm{H}_{2} \mathrm{O}(\mathrm{p}=\mathrm{NS}$, W40). Resting anal pressures in the four groups of patients did not differ significantly,

TABLE II Morbidity after restorative proctocolectomy

\begin{tabular}{lllll}
\hline Reservior design & $\mathfrak{7 3 0}$ & $\mathfrak{7 4 0}$ & W30 & W40 \\
\hline Pelvic sepsis & 3 & 6 & 3 & 1 \\
Wound infection & 0 & 0 & 1 & 1 \\
Bleed per anum & 2 & 1 & 0 & 1 \\
IAAS & 0 & 0 & 2 & 1 \\
SBO & 1 & 2 & 0 & 3 \\
Relaparotomy & 3 & 4 & 1 & 2 \\
E-C fistula & 0 & 1 & 0 & 0 \\
DVT & 0 & 0 & 0 & 1 \\
Pulmonary embolus & 0 & 1 & 0 & 0 \\
Urinary infection & 0 & 0 & 1 & 1
\end{tabular}

Urinary infection

The incidence of postoperative complications was similar in the four groups of patients. IAAS= stricture of the ileoanal the four groups of patients. IAAS = stricture of the ileoanal anastomosis. E-C fistula = enterocutaneous fistula.
bowel obstruction. DVT= deep vein thrombosis. 
TABLE III Clinical functional results according to design of reservoir and length of ileum used (one year after operation)

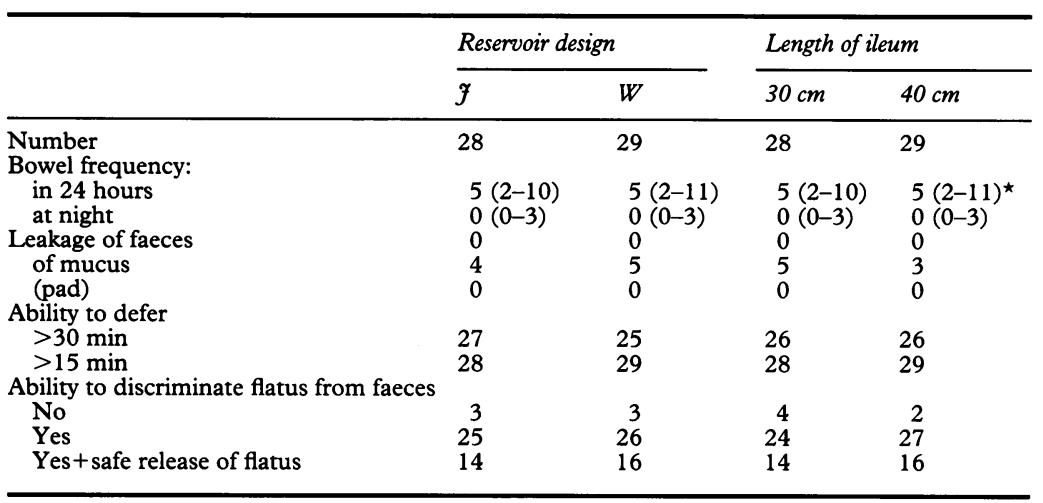

${ }^{\star}$ Median (range), $p=$ NS. For definition of safe, see text.

TABLE IV Clinical results in the four groups one year after operation

\begin{tabular}{|c|c|c|c|c|}
\hline Reservior design & $\mathfrak{7 3 0}$ & $\mathfrak{f 4 0}$ & W30 & W40 \\
\hline Patients (n) & 13 & 15 & 15 & 14 \\
\hline \multicolumn{5}{|l|}{ Bowel frequency: } \\
\hline $\begin{array}{l}\text { in } 24 \text { hours } \\
\text { at night }\end{array}$ & $\begin{array}{l}5(2-8) \\
0(0-1)\end{array}$ & $\begin{array}{l}0(2-10) \\
1(0-3)\end{array}$ & $\begin{array}{l}5(2-10) \\
0(0-3)\end{array}$ & $\begin{array}{l}4(2-11)^{x} \\
0(0-2)\end{array}$ \\
\hline Leakage of faeces & 0 & 0 & 0 & 0 \\
\hline of mucus & 2 & 2 & 3 & 1 \\
\hline (pad) & 0 & 0 & 0 & 0 \\
\hline \multicolumn{5}{|l|}{ Ability to defer } \\
\hline$>30 \mathrm{~min}$ & 13 & 14 & 13 & 12 \\
\hline$>15 \mathrm{~min}$ & 13 & 15 & 15 & 14 \\
\hline \multicolumn{5}{|c|}{ Ability to discriminate flatus from faeces } \\
\hline No & 2 & 1 & 2 & 1 \\
\hline Yes & 11 & 14 & 13 & 13 \\
\hline Yes + safe release of flatus & 6 & 8 & 8 & 8 \\
\hline
\end{tabular}

${ }^{\star}$ Median (range), $p=$ NS. For definition of discrimination, see Methods section.

either before or after operation. However, when all four groups were considered together, median resting anal pressure after operation was $67(49-88) \mathrm{cm} \mathrm{H}_{2} \mathrm{O}$, significantly lower than median resting anal pressure before operation: $93(76-116) \mathrm{cm} \mathrm{H}_{2} \mathrm{O}(\mathrm{p}<0.001)$.

Sensory function - thresholds for sensation in the four groups of patients did not differ significantly, either before or after operation (Fig 4).

Reflex function - the rectoanal inhibitory reflex was present in all patients before operation and in 39 of 50 patients who were tested one year after operation. Loss of the reflex in 11 patients did not correlate with the use of any particular type of reservoir.

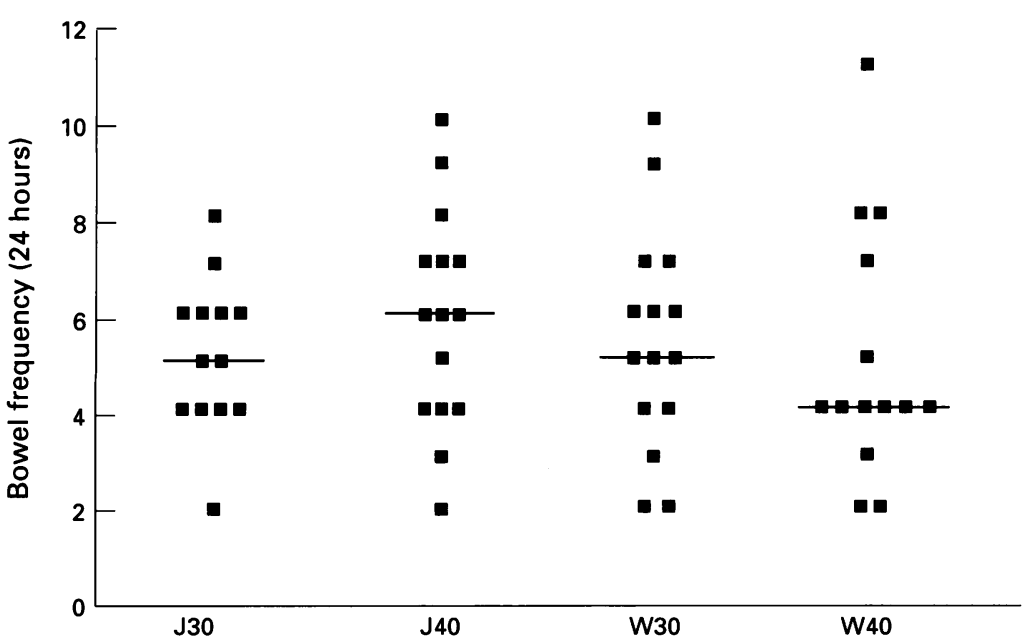

Figure 5: Bowel frequency according to reservoir design. Differences are not significant. Note the wide range of bowel frequency within each group.
Clinical anorectal function (Tables III and IV)

All patients achieved a good degree of anal continence, though eight $(17 \%)$ experienced minor leakage of mucus, especially at night. None had to wear a pad. Duplicated and quadruplicated reservoirs yielded similar results. Also, reservoirs constructed with 30 $\mathrm{cm}$ of ileum gave similar results to those produced by reservoirs made with $40 \mathrm{~cm}$ of ileum. Quadruplicated reservoirs constructed from $40 \mathrm{~cm}$ of ileum yielded slightly better results in terms of bowel frequency than the other three types of reservoir, but the differences were not statistically significant (Fig 5). Bowel frequency in 24 hours bore no relation to the capacity of the reservoir (Fig 6, $r=-0 \cdot 181, \mathrm{p}=0 \cdot 244)$.

Twenty four patients (40\%) regularly used antidiarrhoeal medication, usually codeine phosphate, while a further two patients used it only occasionally. The number of patients requiring antidiarrhoeal medication was the same for each design of reservoir.

The two patients with Crohn's disease and the three patients with indeterminate colitis achieved clinical results that were similar to those of the patients with ulcerative colitis.

\section{Discussion}

This randomised trial is the largest prospective study of the design of the pelvic reservoir in the surgery of ulcerative colitis. Judging by our own previous experience of different types of reservoir ${ }^{56}$ and from the reports of other authors, ${ }^{2314}$ we expected that the more capacious reservoirs made with $40 \mathrm{~cm}$ of ileum and constructed in a quadruplicated (W), 'spherical' configuration would yield better results than the more cylindrical, duplicated $(J)$ reservoir made from $30 \mathrm{~cm}$ of ileum. To our surprise, we found in fact that the $J$ reservoirs provided as good results as the $\mathrm{W}$ reservoirs and that reservoirs made with $30 \mathrm{~cm}$ of ileum produced as good results as those made with $40 \mathrm{~cm}$ of ileum.

Good anorectal function from the patient's point of view after restorative proctocolectomy results from a combination of several desirable end points, such as the ability to defecate spontaneously without needing to intubate the reservoir, the ability to defer defecation, perfect anal continence, and low stool frequency in 24 hours. ${ }^{15}$ Each of the patients in this study was able to defecate spontaneously, which confirms previous findings ${ }^{16-21}$ and shows that both the $J$ and $W$ types of reservoir have overcome the emptying problem that beset the early Parks' triplicated or S reservoirs. ${ }^{1}$ Each of the 57 patients who were available for study one year after operation could defer defecation for longer than 15 minutes and 52 of them $(91 \%)$ could defer defecation for longer than 30 minutes. The ability to defer defecation correlated strongly both with the capacity $(r=0.51 \mathrm{p}<0.001)$ and compliance $(r=0.42 \mathrm{p}=0.004)$ of the reservoir, irrespective of its design. Anal continence was also found to be satisfactory, because none of the patients experienced faecal leakage and only eight 


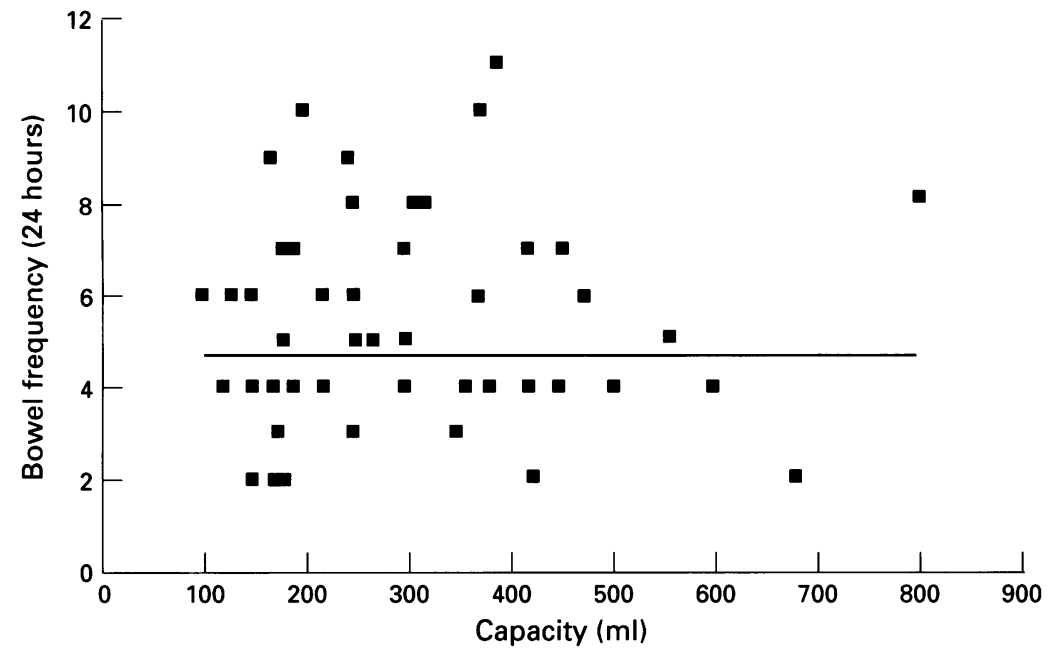

Figure 6: The relation between bowel frequency per 24 hour and the capacity of the ileal reservoir $(\mathrm{r}=-0 \cdot 181, p=0 \cdot 244)$. bore no significant relation to the maximum tolerated volume of the reservoir. The beneficial effect of a pelvic reservoir on stool frequency may therefore reside as much in its ability to modify or 'damp' ileal motility as in the increased capacity that it provides. Interruption of normal ileal peristalsis as ileum enters the reservoir may delay the onset of propulsive wave activity within the reservoir. ${ }^{16} 24-27$ Capacious reservoirs also tend to be more compliant than less capacious ones, 141822 another finding that is supported by the results of this study, as we found that there was a significant correlation $(r=0.365$, $\mathrm{p}=0.012)$ between maximum tolerated volume and compliance.

Overall clinical anorectal function, therefore, reflects the interplay of many factors. Moreover, it is clear that patients who have morphologically and physiologically 'identical' pouches may report wide differences in clinical function. Thus, in this study, five patients had to defecate between nine and 11 times in 24 hours, whereas nine patients only had to defecate two or three times in 24 hours (Fig 5). These contrasting outcomes bore no relation to the design of the pelvic reservoir. Nevertheless, the construction of a pouch that has a certain minimum capacity seems advisable, though what that minimum is remains to be defined. The anal sphincter too, should be left strictly alone to preserve its full motor, sensory, and reflex functions. ${ }^{28}$ Judging by the results of this prospective controlled trial, the extra time and effort invested in the construction of a capacious, quadruplicated (W) reservoir by laborious hand suturing have not been repaid by any significant advantage in terms of overall bowel function when the results are compared with those provided by a comparatively small, duplicated (J) reservoir, which is simple to construct with the aid of linear stapling instruments. provide the greatest volume for any given length of ileum. So much for theory: the actual measurements told a different story! One year after operation, we found that the capacities of the $\mathrm{J} 30, \mathrm{~J} 40, \mathrm{~W} 30$, and $\mathrm{W} 40$ reservoirs were, respectively, 220, 250, 260, and $310 \mathrm{ml}$. Clearly other factors, in addition to the length of ileum used and the shape of the reservoir, must influence reservoir capacity: one such factor is undoubtedly the passage of time, while another may be the strength of the anal sphincter obstructing the exit of the reservoir.

The capacity of the pelvic reservoir has been shown consistently to be the most important factor influencing stool frequency. In that respect, triplicated and quadruplicated reservoir designs have in the main yielded lower stool frequencies than either duplicated reservoirs or no reservoirs ('straight' ileum). ${ }^{162425}$ The capacity of the reservoir increases with time and as it does so stool frequency diminishes, but exactly how the capacity of the reservoir influences stool frequency is not clear. Indeed, reservoir capacity may be less important than has been thought previously: in this study, for example, we found that one year after operation the length of ileum that had been used in the construction of the reservoir
1 Parks AG, Nicholls RJ. Proctocolectomy without ileostomy for ulcerative colitis. $B M \mathcal{F} 1978$; ii: $85-8$.

2 Utsunomiya J, Iwama T, Imajo M, Matsuuo S, Sawai S, Yaegashi K, et al. Total colectomy, mucosal proctectomy and ileo-anal anastomosis. Dis Colon Rectum 1980; 23: 459-66.

3 Nicholls RJ, Pezim ME. Restorative proctocolectomy with ileal reservoir for ulcerative colitis and familial adenomatous polyposis: a comparison of three reservoir designs. Br f Surg 1985; 72: 470-4.

4 Nasmyth DG, Johnston D, Godwin PGR, Dixon MF, Smith A, Williams NS. Factors influencing bowel function after ileal pouch-anal anastomosis. Br $\mathcal{F}$ Surg 1986; 73: 469-73.

5 Nasmyth DG, Williams NS, Johnston D. Comparison of the function of triplicated and duplicated pelvic ileal reservoirs after mucosal proctectomy and ileo-anal anastomosis for ulcerative colitis and adenomatous polyposis. Br $\mathcal{f}$ Surg 1986; 73: 361-6. $A$, Johnston D. Comparison of triplicated (S) and quadruplicated (W) pelvic ileal reservoirs. Gastroenterology 1992; 102: 520-8.

7 Keighley MRB, Yoshioka K, Kmiot W. Prospective randomised trial to compare the stapled double lumen pouch and the sutured quadruple pouch for restorative proctocolectomy. Br f Surg 1988; 75: 1008-11.

8 Johnston D, Holdsworth PJ, Nasmyth DJ, Neal DE, Primrose JN, Womack N, et al. Preservation of the entire Primrose JN, Womack N, et al. Preservation of the entire anal canal in conservative proctocolectomy for ulcerative colitis: a pilot study comparing conservative end-to-end leo-anal anastomosis without mucosal resection with mucosal proctectomy and endo-anal anastomosis. $\mathrm{Br} \mathcal{F}$ Surg 1987, 74: 940-4.

Lewis WG, Holdsworth PJ, Sagar PM, Holmfield JHM, proctocolectomy on anal sphincter function. $\mathrm{Br} \mathcal{F}$ Surg 1993; 80: 121-3.
6 Sagar PM, Holdsworth PJ, Godwin PGR, Quirke P, Smith Johnston D. Effect of anorectal eversion during restorative 
10 Holdsworth PJ, Johnston D. Anal sensation after restorative proctocolectomy for ulcerative colitis. Br f Surg 1988; 75: 993-6.

11 Roe AM, Bartolo DCC, Mortensen NJMcM. A new method for assessment of anal sensation in various anorectal disorders. Br f Surg 1986; 73: 310-2.

12 Keighley MRB, Henry MM, Bartolo DCC, Mortensen NJM. Anorectal physiology measurement: report of a working party. Br $\mathcal{F}$ Surg 1989; 75: 356-7.

13 Altman DG. Practical statistics for medical research. London: Chapman and Hall, 1991.

14 Hallgren T, Fasth S, Nordgren S, Oresland T, Hallsberg I Hullen L, Fasth S, Nordgren S, Oresland T, Hallsberg L, Hulten L. Manovolumetric characteristics and functional results in

15 Levitt MD, Lewis AAM. Determinants of ileoanal pouch function. Gut 1991; 32: 126-7.

16 Pescatori M, Parks AG. The sphincteric and sensory components of preserved continence after ileoanal reservoir. Surg Gynecol Obstet 1984; 158: 517-21.

17 Dozois RR. In Symposium. Restorative proctocolectomy with ileal reservoir. Int 7 Colorect Dis 1986; 1: 2-19.

18 Utsunomiya J. In Symposium. Restorative proctocolectomy with ileal reservoir. Int $\mathcal{F}$ Colorect Dis 1986; 1: 2-19.

19 O'Connell PR, Pemberton JH, Brown ML, Kelly KA. Determinants of stool frequency after ileal pouch-anal anastomosis. Am f Surg 1987; 153: 157-64.

20 Martin LW, Fischer JE. Preservation of anorectal continence following total colectomy. Ann Surg 1982; 196: $700-4$
21 Mortensen NJM. Progress with the pouch Gut 1988; 29: 561-5.

22 Sagar PM, Holdsworth PJ, Johnston D. Correlation between laboratory findings and clinical outcome after restorative proctocolectomy; serial studies in 20 patients with end-to-end pouch-anal anastomosis. Br f Surg 1991; 78: $67-70$.

23 Thompson WHF, Simpson AHRW, Wheeler JL. Mathematical prediction of ileal pouch capacity. Brf Surg 1987; 74: 567-8.

24 Taylor BM, Beart RW Jr, Dozois RR, Kelly KA, Phillips SF. Straight ileo-anal anastomosis versus ileal pouch-anal anastomosis after colectomy and mucosal proctectomy. Arch Surg 1983; 118: 696-701.

25 Taylor BM, Cranley B, Kelly KA, Phillips SF, Beart RW Jr, Dozois RR. A clinico-physiological comparison of ileal pouch-anal and straight ileo-anal anastomoses. Ann Surg 1983; 198: 462-8

26 Rabau MY, Percy JP, Parks AG. Ileal pelvic reservoir a correlation between motor patterns and clinical behaviour. Brf Surg 1982; 69: 391-5.

27 Stryker SJ, Borody TJ, Phillips SF, Kelly KA, Dozois RR, Beart RW Jr. Motility of the small intestine after proctocolectomy and ileal pouch-anal anastomosis. Ann Surg 1985; 201: 351-6.

28 Lewis WG, Williamson MER, Miller AS, Sagar PM, Holdsworth PJ, Axon ATR, et al. Preservation of complete anal sphincteric function in the course of restorative proctocolectomy: The rectoanal inhibitory reflex and fine control of continence need not be impaired. Gut 1995; 35: 902-6. 